2 Turleau C, de Grouchy J, Chavin-Colin F, Roubin M. Trisomie 15q distale. Ann Genet (Paris) 1977;20:214-6.

3 Zabel B, Baumann W. Trisomie partielle pour la partie distale du bras long du chromosome 15 par translocation X/15 maternelle. Ann Genet (Paris) 1977;20:285-9.

4 Tzancheva M, Krachounova M, Damjanova $Z$. Two familial cases with trisomy $15 q$ dist due to a $\operatorname{rcp}(5 ; 15)$ (p14;q21). Hum Genet 1981;56:275-7.

5 Pai GS, Thomas GH, Mahoney W, Migeon BR. Complex chromosome rearrangements. Report of a new case and literature review. Clin Genet 1980;18:436-44.

Requests for reprints to Dr Patricia N HowardPeebles, Laboratory of Medical Genetics, University Station, Birmingham, Alabama 35294, USA.

\section{Familial pericentric inversion of chromosome 13 resulting in duplication $13 \mathrm{q} 22 \rightarrow$ qter}

SUMMARY A 10-year-old male with a recombinant (13)dup q chromosome is reported. The recombinant chromosome originated from a maternal pericentric inversion which was present in two of his four normal sibs. A segregation analysis of 60 pregnancies from which one of the parents was a carrier of inv(13) showed a significant predominance of males among the viable offspring.

Cases with duplication of a distal 13q segment have led to the detection of familial pericentric inversions

Received for publication 8 October 1981 of chromosome 13. De novo rearrangements between the homologous chromosomes 13 seem to be rare. ${ }^{1}$ Another case of duplication 13q (distal) originating from a maternal pericentric inversion is presented here.

\section{Case report}

The proband, a male, was born in 1969 , the fifth child of healthy non-consanguineous parents. At the time of birth his mother was 37 and his father 38 years old. The other four children were normal. There was no family history of abortions, birth defects, or mental retardation (fig 1).

At the age of 10 years his height was $113 \mathrm{~cm}$, below the 3rd centile. He had severe psychomotor retardation, spastic diplegia of the legs, and myoclonic and akinetic seizures. The facial appearance was characteristic of partial trisomy for the distal segment of 13q (fig 2). The thumbs and big toes

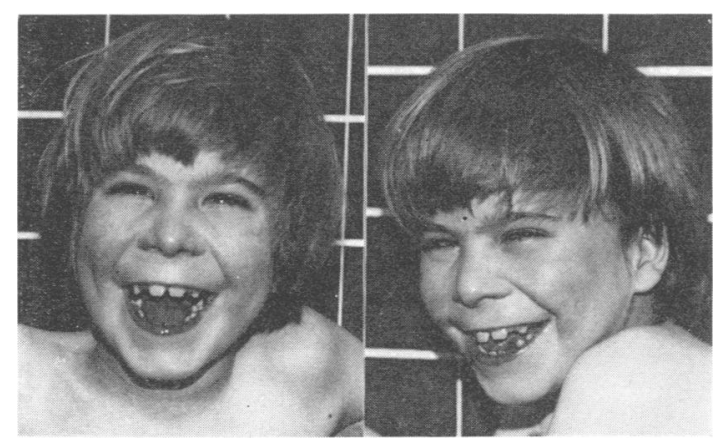

FIG 2 Proband at 10 years of age.

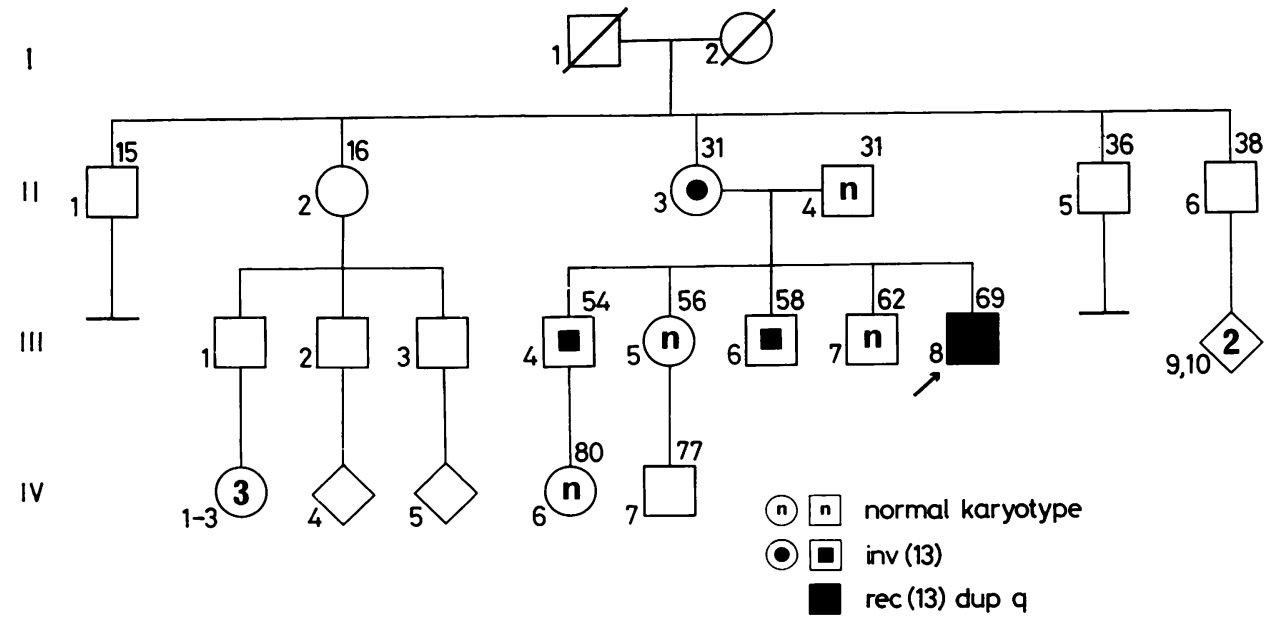

FIG 1 Family pedigree including years of birth. 
were short and broad and he had tapering fingers with hyperconvex nails. Palmar and plantar dermatoglyphs corresponded with the cases of distal trisomy 13q originating from familial translocations, inversions, or de novo previously reviewed by Habedank. ${ }^{1}$ In the carrier mother some special features were present on the palms.

Computerised tomography showed moderate enlargement of the ventricular system. Laboratory findings included a normal fetal haemoglobin value and no increased nuclear projections of neutrophils. The patient and both parents had an esterase D type 1-1.

Chromosome analysis on peripheral blood lymphocytes by $\mathbf{G}$ banding, $\mathrm{C}$ banding after $\mathrm{Q}$ banding, and NOR silver staining showed a chromosome complement of $46, X Y, 13 p+$ in the proband. One chromosome 13 carried an additional segment $13 q 22 \rightarrow$ qter on its short arm. Its $C$ banded centromeric region was distinctly smaller and more weakly stained than those present in the other D chromosomes and the NOR silver staining was negative.

The family study revealed that the mother and two brothers carried an inv(13)(p11q21) with $\mathrm{Ag}$ positive NORs and distinct satellites on the distal band q21 of the long arm. Its constitutive heterochromatin was distributed between the centromeric region and the distal end of the long arm (fig 3).

The father, two sibs, and a child of a carrier brother had normal karyotypes.

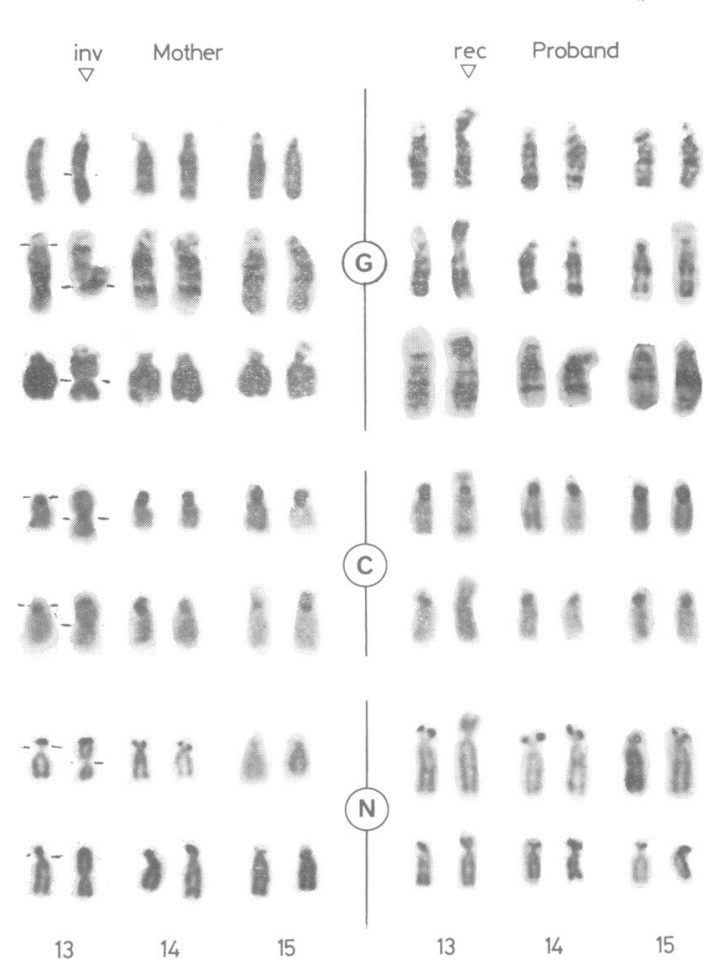

FIG 3 D group chromosomes from the inversion carrier mother and the proband with 46,XY,rec(13)dup $q$, inv(13)(p11q21)mat. $G$ and $C$ banding (after $Q$ banding) and NOR silver staining.

TABLE Segregation analysis of inv (13) carriers

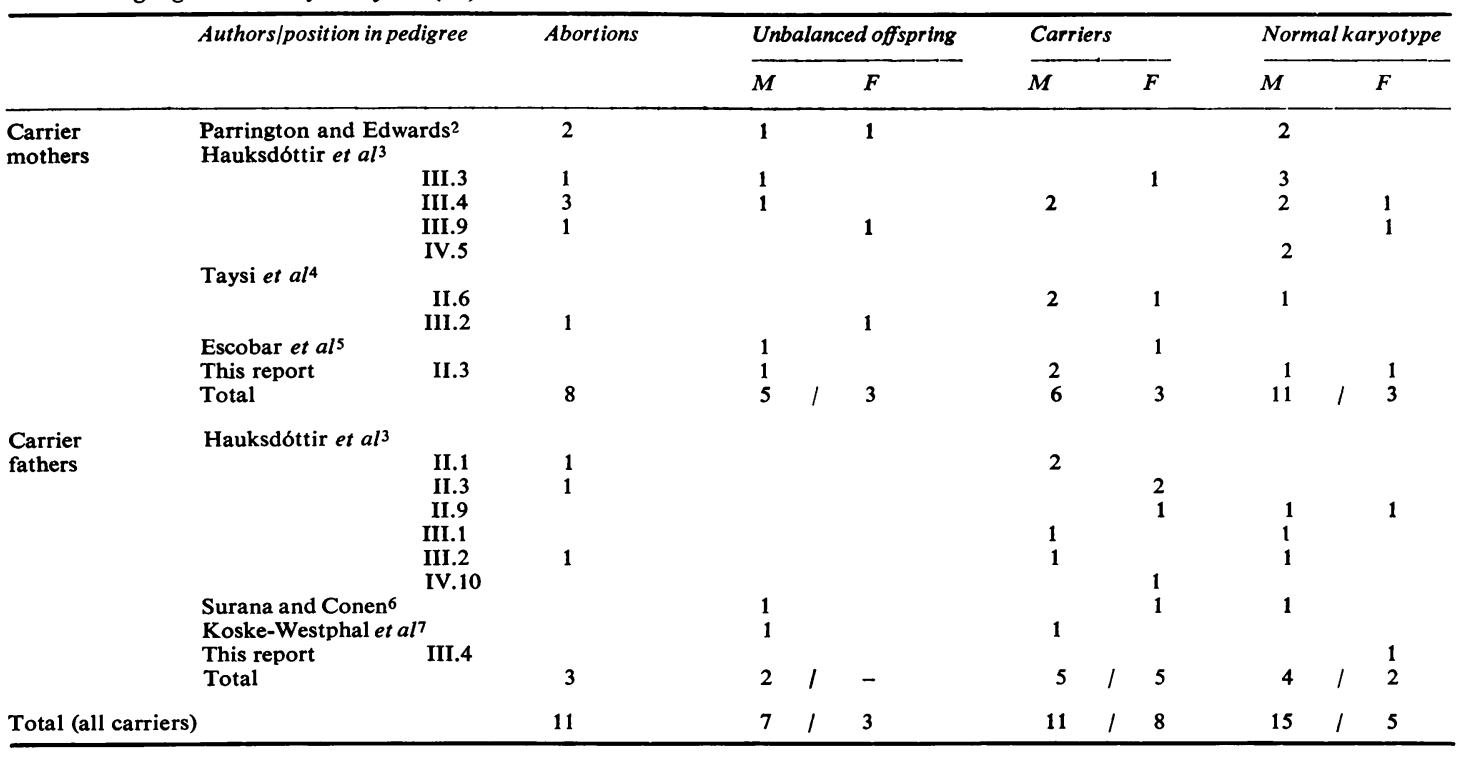




\section{Discussion}

The segregation analysis of 60 pregnancies shows that among all viable offspring from inv(13) carriers there is a significant predominance of males (table). This observation suggests a selection against female offspring. However, the reason for this selection remains obscure.

This paper is dedicated to Professor Doctor H Schönenberg, Aachen, on his 65th birthday.

The author gratefully acknowledges the excellent assistance of Mrs Eva-Maria Bergmann and Heidi Schuster, and thanks Professor A Rodewald, Homburg, for the dermatoglyphic and esterase D studies, and Dr Roebruck, Aachen, for the statistical calculation of the segregation analysis.

\section{HABEDANK \\ Lehr- und Forschungsgebiet Klinische Cytogenetik, Medizinische Fakultät der RWTH Aachen, Federal Republic of Germany}

\section{References}

1 Habedank M. Partial trisomy 13q21 $\rightarrow$ qter de novo due to a recombinant chromosome rec(13)dup q. Hum Genet 1979;52:91-9.

2 Parrington JM, Edwards JH. Patau's syndrome with $\mathrm{D}_{1}$ duplication-deficiency derived from a maternal $\mathbf{D}$ group pericentric inversion. Ann Hum Genet 1971;35:35-45.

3 Hauksdóttir H, Halldórsson S, Jensson O, Mikkelsen M, McDermott A. Pericentric inversion of chromosome no 13 in a large family leading to duplication deficiency causing congenital malformations in three individuals. J Med Genet 1972;9:413-21.

4 Taysi K, Bobrow M, Balci S, Madan K, Atasu M, Say B. Duplication/deficiency product of a pericentric inversion in man: a cause of $D_{1}$ trisomy syndrome. $J$ Pediatr 1973; $82: 263-8$.

5 Escobar JI, Sanchez O, Yunis JJ. Trisomy for the distal segment of chromosome 13. Am J Dis Child 1974;128: 217-20.

6 Surana RB, Conen PE. Inherited pericentric inversion of a group D (13-15) chromosome. J Med Genet 1972;9: 105-10.

7 Koske-Westphal T, Pruszak-Seel RE, Niss R, Passarge E. Partial trisomy 13 presumably due to recombination in an inversion heterozygote and by unequal crossing-over. Ann Hum Genet 1978;41:315-22.

Requests for reprints to Professor M Habedank, Klinikum RWTH, D-5100 Aachen, Federal Republic of Germany.

\section{Two Robertsonian translocations in a boy with mental retardation*}

SUMMARY An 8-year-old boy with mental retardation was found to be a mosaic, showing three different cell lines, 46,XY/46,XY,-21, $+\mathrm{t}(\mathrm{q} 21 \mathrm{q} 21) / 45, X Y,-13,-21,+\mathrm{t}(\mathrm{q} 13 \mathrm{q} 21)$ in cultured peripheral blood cells.

Reports of structural mosaicism involving two different Robertsonian translocations are very few. ${ }^{12}$ We report here a very unusual case of a boy with no clinical signs of Down syndrome carrying two different Robertsonian translocations and a normal cell line.

\section{Case report}

The patient (fig 1) was born in January 1968 after

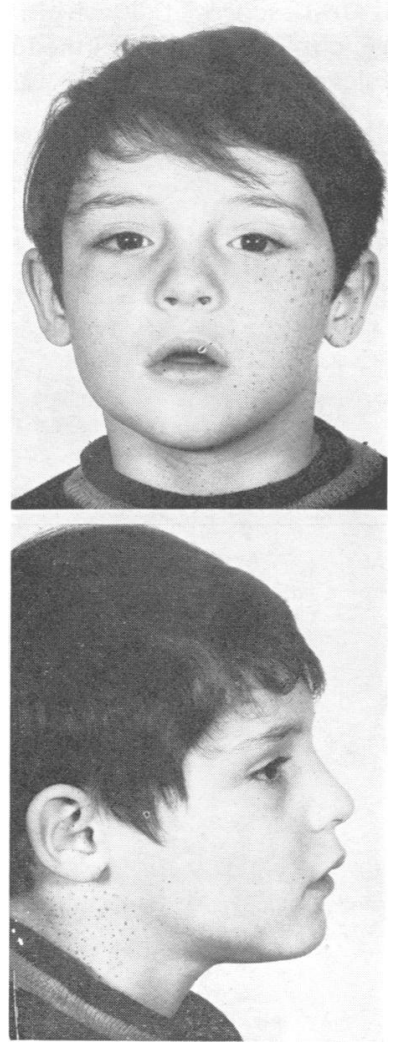

FIG 1 Patient at 6 years of age: full face and profile. Note: photographic artefacts (speckled pattern).

*This work was partially supported by The Birth Defects Institute, New York State, Department of Health. Received for publication 16 May 1981. 